\title{
High serum HTATIP2/TIP30 level in serous ovarian cancer as prognostic or diagnostic marker
}

\author{
Yakup Kumtepe ${ }^{1}$, Zekai Halici ${ }^{*}$, Ozlem Sengul ${ }^{3}$, Celalettin Semih Kunak ${ }^{4}$, Yasin Bayir ${ }^{5}$, Nergiz Kilic ${ }^{6}$, Elif Cadirci ${ }^{7}$, \\ Alparslan Pulur ${ }^{7}$ and Zafer Bayraktutan ${ }^{8}$
}

\begin{abstract}
Background: Human HIV-1 TAT interactive protein 2 (HTATIP2/TIP30) is an evolutionarily conserved gene that is expressed ubiquitously in human tissues and some tumor tissues. This protein has been found to be associated with some gynecological cancers; as such, this study aimed to investigate blood HTATIP2/TIP30 levels in patients with ovarian cancer.

Methods: Twenty-three women with ovarian cancer and 18 patients with various non-cancerous gynecological complaints (for example, dysfunctional uterine bleeding, fibroids, and urinary incontinence) were included in the study. The pathological diagnosis of ovarian cancer was adenocarcinoma. HTATIP2/TIP30 concentration in the patients' blood samples was determined using ELISA kits.

Results: The HTATIP2/TIP30 level was significantly higher in the cancer group than in the control group $(1.84 \pm 0.82$ versus $0.57 \pm 0.13 \mathrm{ng} / \mathrm{ml}$, mean $\pm \mathrm{SD}$ ).

Conclusions: We demonstrated the potential role of HTATIP2/TIP30 in ovarian cancer for the first time, thereby enlightening future studies targeting HTATIP2/TIP30 in ovarian cancer treatment, diagnosis, and prevention.
\end{abstract}

Keywords: HTATIP2/TIP30, ovarian cancer, adenocarcinoma

\section{Background}

Ovarian cancer is the seventh most common cancer in women in terms of both incidence and mortality. The histologic subtypes of ovarian cancer are epithelioid (serous, endometrioid, mucinous, clear cell, and undifferentiated) and non-epithelioid [1]; the epithelioid subtype accounts for $90 \%$ of malignancies [2]. The onset is often insidious; the symptoms are vague and may mimic other conditions. This may lead to a delay in diagnosis, and currently, three-quarters of women with ovarian cancer are diagnosed when the disease has spread throughout the abdomen $[3,4]$.

Many factors affect cell growth and related abnormal tumor growth in ovarian cancer. Epidermal growth factor receptor (EGFR) is also central to the promotion of cell growth and has a role in the development of cancer. Therefore, preventing EGFR activity is an attractive

\footnotetext{
* Correspondence: hzekai@atauni.edu.tr

${ }^{2}$ Department of Pharmacology, Faculty of Medicine, Ataturk University, Erzurum 25240, Turkey

Full list of author information is available at the end of the article
}

target for novel therapeutic agents. EGFR is a member of a family of similar molecules called the epidermal growth factor receptor family. This family also includes human epidermal growth factor receptor 2 (HER2/neu), Erb3, and Erb4. HER2/neu overexpression is related to poor outcome in breast and ovarian cancers [5-8]. A monoclonal antibody, trastuzumab (Herceptin), has been developed that binds to HER2/neu [5,6]. A $7.3 \%$ response rate was demonstrated, with no significant toxicity, in women with recurrent ovarian cancer treated with Herceptin [9]. In addition to these studies demonstrating the role of HER2/ neu in gynecological cancers, Zhang et al. reported that overexpression of human HIV-1 TAT interactive protein 2 (HTATIP2/TIP30) is associated with HER2/neu status in breast cancer [10].

HTATIP2/TIP30 is an evolutionarily conserved gene that is expressed ubiquitously in human tissues and some tumor tissues. HTATIP2/TIP30 has been shown to be bound to the transcriptional activation domain of the human immunodeficiency virus (HIV-1) TAT and to act as a cofactor to specifically enhanced TAT-activated

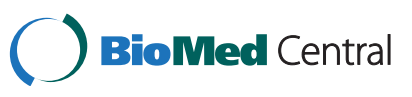


transcription [11]. The discovery of the roles of HTATIP2/ TIP30 in apoptosis and tumor suppression, especially in controlling the expression of genes involved in apoptosis and metastasis suppression, indicates that there is a signal pathway facilitated by HTATIP2/TIP30 and its associated factors [12-17]. It also interacts with an estrogen receptor $\alpha(E R \alpha)$-interacting coactivator CIA and regulates $E R \alpha-$ mediated c-Myc transcription [18,19]. All of this information led us to hypothesize a potential role of HTATIP2/ TIP30 in ovarian cancer.

The aim of our study was to investigate the levels of HTATIP2/TIP30 in serous ovarian cancers, using the enzyme-linked immunosorbent assay (ELISA) method, and to determine whether altered HTATIP2/TIP30 levels correlate with cancer occurrence.

\section{Methods \\ Patients}

Between March 2009 and February 2010, 34 patients who were suspected of having ovarian cancer and who visited Ataturk University, Faculty of Medicine, Department of Obstetrics and Gynecology, were evaluated in this study. Before surgery, whole abdominopelvic magnetic resonance imaging, vaginal ultrasound, and $\mathrm{Ca}$ 125 level testing were performed to determine the presence of tumors and ascites, according to our routine clinical approach, and $5 \mathrm{ml}$ of blood were taken. This study was approved by the Local Human Ethics Committee of the Ministry of Health.

All of the patients underwent radical cytoreductive surgery to remove all visible tumors, including hysterectomy, bilateral salpingo-oophorectomy, appendectomy, infracolic omentectomy, and systemic pelvic and paraaortic lymphadenectomy. Based on the final pathology results, those confirmed to have serous ovarian cancer ( $\mathrm{n}=23$, stages III and IV) were included in the final data analysis of the study group. After surgical intervention, the treatment of 11 patients with other cancer types (mucinous, $\mathrm{n}=5$; endometrioid, $\mathrm{n}=4$; clear cell, $\mathrm{n}=1$; and Brenner cell, $\mathrm{n}=1$ ) was continued with platinumbased chemotherapy, but they were excluded from the data analysis.

The 23 patients diagnosed with epithelial serous ovarian cancer (grade $\mathrm{I}, \mathrm{n}=4$; grade II, $\mathrm{n}=13$; and grade III, $\mathrm{n}=6$ ) were chosen for the study group. During the same patient selection period, 18 patients with various noncancerous gynecological complaints (dysfunctional uterine bleeding, $\mathrm{n}=6$; fibroids, $\mathrm{n}=7$; urinary incontinence, $\mathrm{n}=3$; and endometrioma, $\mathrm{n}=2$ ) who were referred to our polyclinics were chosen for the control group. The ages of the subjects in the control group were matched with the ages of the subjects in the study group. All procedures were reviewed and approved by the Institutional Ethics
Committee on Human and Animal Research. All subjects were given an explanation regarding the aim of the study.

\section{Blood sampling}

Blood samples were collected from these patients in biochemical tubes and immediately taken to the biochemistry laboratory, where they were centrifuged at 4,000 rpm for 10 minutes at $5^{\circ} \mathrm{C}$, and sera was obtained. The sera were kept at $-80^{\circ} \mathrm{C}$ until the biochemical measurements for HTATIP2/TIP30 evaluation were conducted.

\section{Biochemical analyses}

HTATIP2/TIP30 concentration was determined using a commercially available ELISA kit (Cusabio Biotech Co., Ltd.(Incubator Building 4th floor, Wuhan University Science Park,No.te-1, Daxueyuan Road, Donghu Hi-Tech Development Area, Wuhan, Hubei Province 430223, P.R. China) catalog number: CSB-E14917H ELISA kit). For this kit, the minimum detectable dose of human HTATIP2 is typically less than $0.16 \mathrm{ng} / \mathrm{ml}$. The sensitivity of this assay, or lower limit of detection (LLD), was defined as the lowest protein concentration that could be differentiated from zero. Intra-assay precision (precision within an assay) is CV\% < 8\%, and inter-assay precision (precision between assays) is CV\% $<10 \%$.

\section{Statistical analyses}

The IBM SPSS Statistics 20 (IBM Corporation Software Group Route 100 Somers, NY 10589)computer program package was used for statistical calculations. The results were expressed as mean \pm standard deviation (SD). Unpaired Student's $t$-tests were used to analyze the significant differences in HTATIP2/TIP30 levels between the control and ovarian cancer groups.

\section{Results}

The women's age ranges were 42 to 81 years (mean age, $65 \pm 24$ years) in the study group and 39 to 78 years (mean age, $59 \pm 22$ years) in the control group. The mean parity was 4.2 (1 to 8 ) in the study group and 4.3 ( 2 to 8$)$ in the control group. Only a few patients $(n=4)$ in the two groups combined were smokers.

As seen in Figure 1, the HTATIP2/TIP30 level was significantly higher in the cancer group than in the control group $(1.8363 \pm 0.8177$ (minimum: 0.82 to maximum: 3.67 ) versus $0.5659 \pm 0.127$ (minimum: 0.36 to maximum: $0.79) \mathrm{ng} / \mathrm{ml}$, respectively).

\section{Discussion}

Clinical studies regarding the status of HTATIP2/TIP30 expression in cancer patients are limited. The aim of this study was to demonstrate the involvement of HTATIP2/ TIP30 in advanced epithelial serous ovarian cancer. Tong et al. [20] showed that downregulation of HTATIP2/TIP30 


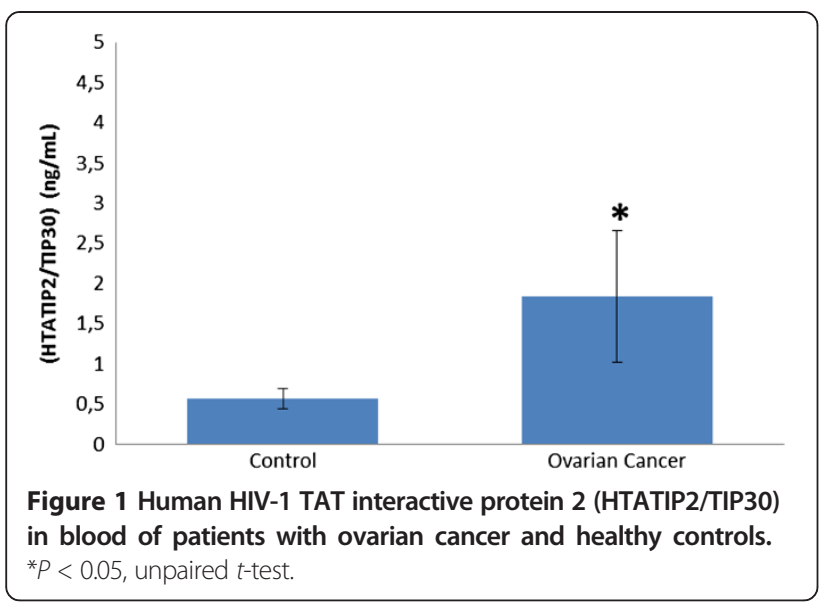

promoted metastasis in lung cancer. Downregulation of HTATIP2/TIP30 has also been observed in other cancer types, including melanoma, colon cancer, breast cancer, neuroblastoma, and hepatocellular carcinoma $[13,14,16]$. Several cell culture studies have demonstrated the role of HTATIP2/TIP30 in a number of tumor cell lines, including neuroblastoma, breast cancer, glioblastoma, and melanoma. In the present study, we found that HTATIP2/TIP30 levels were elevated in the serum samples of patients with ovarian cancer.

HTATIP2/TIP30 is an evolutionarily conserved gene that is expressed ubiquitously in human tissues and some tumor tissues [11]. It is known that there has been very significant progress in the development of anti-cancer agents, including tyrosine kinase inhibitors, angiogenesis inhibitors, and agents that interact with the cell cycle and cell death (apoptosis). HTATIP2/TIP30 displays a serinethreonine kinase activity that can phosphorylate the carboxyl terminal domain of RNA polymerase II in a TATdependent manner [12], suggesting that HTATIP2/TIP30 is a potential target for human cancer treatment. In addition, increasing evidence suggests that receptor tyrosine kinase activation participates in the oncogenic progression from the non-neoplastic mesothelial lining of the ovaries or the fallopian tube epithelium to epithelial ovarian cancer [21]. In light of these data, we can suggest that the increase in HTATIP2/TIP30 levels in ovarian cancer may be related to its intrinsic protein kinase activity.

The discovery of the roles of HTATIP2/TIP30 in apoptosis and tumor suppression, especially in controlling the expression of genes involved in apoptosis and metastasis suppression, indicates that there is a signal pathway facilitated by HTATIP2/TIP30 and its associated factors [12-17]. The literature shows that it is believed that the mechanism of HTATIP2/TIP30's anti-metastatic properties is that it inhibits angiogenic properties of tumor cells and predisposes tumor cells to apoptosis [14,22]. Consistent with the role of HTATIP2/TIP30 in the suppression of tumor growth and metastasis via transcription mechanisms, studies have revealed that the ectopic expression of HTATIP2/TIP30 in tumor cell lines upregulates the expression of pro-apoptotic factors [12] and angiogenic inhibitors, and downregulates the expression of angiogenic stimulators [14]. In our study, the increased HTATIP2/ TIP30 levels in the blood samples might be a response to increased angiogenesis in tumors.

HTATIP2/TIP30 also interacts with an estrogen receptor $\alpha$-interacting coactivator and regulates ER $\alpha$-mediated c-Myc transcription $[18,19]$, suggesting that it has a role in ovarian cancer. Most of the effects of estrogen are facilitated by estrogen receptor $\alpha$, which controls a number of hormone-responsive genes $[23,24]$ including the c-Myc gene, which is important for cell proliferation [25-28]. The finding that HTATIP2/TIP30 acts as a negative regulator in both unliganded and liganded ER $\alpha$-mediated c-Myc expression suggests that HTATIP2/TIP30 might regulate tumorigenesis and tissue development in ER $\alpha$-targeted organs $[29,30]$. In addition, in our study, it was found that elevated HTATIP2/TIP30 levels might affect ovaries as ER $\alpha$-targeted organs.

On the other hand, overexpression of HER $2 /$ neu, a member of the EGFR family, is related to poor outcomes in breast cancer $[5,6]$ and ovarian cancer $[7,8]$. Studies are underway with oral agents that inhibit the tyrosine kinase activity associated with two oncogenes - EGFR and HER2/ neu. In addition to these studies demonstrating the role of HER2/neu in gynecological cancers, Zhang et al. reported that overproduction of HTATIP2/TIP30 is associated with HER2/neu status in breast cancer [10]. All of these studies support our findings that HTATIP2/TIP30 has a potential role in ovarian cancer, and that HER2/neu expression may be related to increased HTATIP2/TIP30 levels.

\section{Conclusion}

In this study, we demonstrated for the first time a potential role of HTATIP2/TIP30 in ovarian cancer which will enlighten future studies targeting HTATIP2/TIP30 in ovarian cancer treatment, diagnosis, and prevention. At the clinical level, our study is unable to suggest whether HTATIP2/TIP30 expression is suppressed or enhanced at the onset of ovarian cancers, when it is confined to the ovaries. Future clinical and experimental studies are required to determine the conclusive role of HTATIP2/ TIP30 in ovarian cancer.

\section{Abbreviations}

EGFR: Epidermal growth factor receptor; ELISA: Enzyme-linked immunosorbent assay; ERa: Estrogen receptor a; HER2/neu: Human epidermal growth factor receptor 2; HIV-1: Human immunodeficiency virus; HTATIP2/TIP30: Human HIV-1 TAT interactive protein 2; LLD: Lower limit of detection.

\section{Competing interest}

The authors declare that they have no competing interest. 


\section{Authors' contributions}

YK: Designed and controlled whole sections of the study with ZH. ZH: Designed and controlled whole sections of the study with YK. OS: Analyzed and clinically evaluated patients with NK and AP. CSK: Performed statistical analyses with EC. YB: Performed all biochemical analyses with ZB. NK: Analyzed and clinically evaluated patients with OS and AP. EC: Performed statistical analyses with CSK and wrote down manuscript in English. AP: Analyzed and clinically evaluated patients with OS and NK. ZB: Performed all biochemical analyses with YB. All authors read and approved the final manuscript.

\section{Acknowledgments}

This research has been supported by Ataturk University Scientific Research Projects Coordination Commission (ATAUNI-BAP) with project number '2011/1'.

\section{Author details}

'Department of Obstetrics and Gynecology, Ataturk University, Faculty of Medicine, Erzurum 25240, Turkey. ${ }^{2}$ Department of Pharmacology, Faculty of Medicine, Ataturk University, Erzurum 25240, Turkey. ${ }^{3}$ Department of Gynecology and Obstetrics, Yenimahalle Government Hospital, Ankara 06170 Yenimahalle, Turkey. ${ }^{4}$ Department of Pharmacology, Faculty of Medicine, Giresun University, Giresun 28100, Turkey. ${ }^{5}$ Department of Biochemistry, Faculty of Pharmacy, Ataturk University, Erzurum 25240, Turkey. ${ }^{6}$ Department of Obstetrics and Gynecology, Faculty of Medicine, Kafkas University, Kars 36000, Turkey. ${ }^{7}$ Department of Pharmacology, Faculty of Pharmacy, Ataturk University, Erzurum 25240, Turkey. ${ }^{8}$ Department of Biochemistry, Erzurum Region Education and Research Hospital, Erzurum 25240, Turkey.

Received: 23 October 2012 Accepted: 31 May 2013

Published: 24 June 2013

\section{References}

1. Siwak DR, Carey M, Hennessy BT, Nguyen CT, McGahren Murray MJ, Nolden L, Mills GB: Targeting the epidermal growth factor receptor in epithelial ovarian cancer: current knowledge and future challenges. J Oncol 2010, 2010:568938.

2. Feeley KM, Wells M: Precursor lesions of ovarian epithelial malignancy. Histopathology 2001, 38:87-95.

3. Haldar K, Gaitskell K, Bryant A, Nicum S, Kehoe S, Morrison J: Epidermal growth factor receptor blockers for the treatment of ovarian cancer. Cochrane Database Syst Rev 2011, 5, CD007927.

4. Shepherd JH: Revised FIGO staging for gynecological cancer. Br J Obstet Gynecol 1989, 96:889-892.

5. Baselga J, Albanell J, Molina MA, Arribas J: Mechanism of action of trastuzumab and scientific update. Semin Oncol 2001, 28:4-11.

6. Cooley S, Burns LJ, Repka T, Miller JS: Natural killer cell cytotoxicity of breast cancer targets is enhanced by two distinct mechanisms of antibody-dependent cellular cytotoxicity against LFA-3 and HER2/neu. Exp Hematol 1999, 27:1533-1541.

7. Chase DM, Mathur N, Tewari KS: Drug discovery in ovarian cancer. Recent Pat Anticancer Drug Discov 2010, 5:251-260.

8. Tomsova M, Melichar B: Contribution of immunohistochemistry in prognostic assessment of epithelial ovarian carcinoma - review of the literature I. Acta Medica (Hradec Kralove) 2006, 49:161-165.

9. Bookman MA, Darcy KM, Clarke-Pearson D, Boothby RA, Horowitz IR: Evaluation of monoclonal humanized anti-HER2 antibody, trastuzumab, in patients with recurrent or refractory ovarian or primary peritoneal carcinoma with overexpression of HER2: a phase II trial of the Gynecologic Oncology Group. J Clin Oncol 2003, 21:283-290.

10. Zhang DH, Wong LL, Tai LK, Koay ES, Hewitt RE: Overexpression of CC3/ TIP30 is associated with HER2/neu status in breast cancer. J Cancer Res Clin Oncol 2005, 131:603-608.

11. Xiao H, Tao Y, Greenblatt J, Roeder RG: A cofactor, TIP30, specifically enhances HIV-1 Tat-activated transcription. Proc Natl Acad Sci USA 1998, 95:2146-2151

12. Xiao H, Palhan V, Yang Y, Roeder RG: TIP30 has an intrinsic kinase activity required for up-regulation of a subset of apoptotic genes. EMBO J 2000, 19:956-963.

13. Ito M, Jiang C, Krumm K, Zhang X, Pecha J, Zhao J, Guo Y, Roeder RG, Xiao H: TIP30 deficiency increases susceptibility to tumorigenesis. Cancer Res 2003, 63:8763-8767.

14. NicAmhlaoibh R, Shtivelman E: Metastasis suppressor CC3 inhibits angiogenic properties of tumor cells in vitro. Oncogene 2001, 20:270-275
15. Shi M, Zhang $X$, Wang $P$, Zhang HW, Zhang BH, Wu MC: TIP30 regulates apoptosis-related genes in its apoptotic signal transduction pathway. World J Gastroenterol 2005, 11:221-227.

16. Shtivelman E: A link between metastasis and resistance to apoptosis of variant small cell lung carcinoma. Oncogene 1997, 14:2167-2173.

17. Zhao J, Zhang X, Shi M, Xu H, Jin J, Ni H, Yang S, Dai J, Wu M, Guo Y: TIP30 inhibits growth of $\mathrm{HCC}$ cell lines and inhibits $\mathrm{HCC}$ xenografts in mice in combination with 5-FU. Hepatology 2006, 44:205-215.

18. Jiang C, Ito M, Piening V, Bruck K, Roeder RG, Xiao H: TIP30 interacts with an estrogen receptor alpha-interacting coactivator $\mathrm{CIA}$ and regulates c-Myc transcription. J Biol Chem 2004, 279:27781-27789.

19. Wang $\mathrm{S}$, Zhao B, Zhang $\mathrm{S}$, Ji H: Cloning, expression, purification, and characterization of AmphiTip30, a member of short-chain dehydrogenases/ reductases family from the amphioxus Branchiostoma belcheri tsingtauense. Protein Expr Purif 2008, 57:63-71.

20. Tong X, Li K, Luo Z, Lu B, Liu X, Wang T, Pang M, Liang B, Tan M, Wu M, Zhao J, Guo Y: Decreased TIP30 expression promotes tumor metastasis in lung cancer. Am J Pathol 2009, 174:1931-1939.

21. Jiao Y, Ou W, Meng F, Zhou H, Wang A: Targeting HSP90 in ovarian cancers with multiple receptor tyrosine kinase coactivation. Mol Cancer 2011, 10:125.

22. Whitman S, Wang X, Shalaby R, Shtivelman E: Alternatively spliced products CC3 and TC3 have opposing effects on apoptosis. Mol Cell Biol 2000, 20:583-593.

23. Nilsson S, Makela S, Treuter E, Tujague M, Thomsen J, Andersson G, Enmark E, Pettersson K, Warner M, Gustafsson JA: Mechanisms of estrogen action. Physiol Rev 2001, 81:1535-1565.

24. Planas-Silva MD, Shang Y, Donaher JL, Brown M, Weinberg RA: AlB1 enhances estrogen-dependent induction of cyclin D1 expression. Cancer Res 2001, 61:3858-3862.

25. Battey J, Moulding C, Taub R, Murphy W, Stewart T, Potter H, Lenoir G, Leder $P$ : The human c-Myc oncogene: structural consequences of translocation into the IgH locus in Burkitt lymphoma. Cell 1983, 34:779-787

26. Dubik D, Shiu RP: Mechanism of estrogen activation of c-Myc oncogene expression. Oncogene 1992, 7:1587-1594.

27. Leder A, Pattengale PK, Kuo A, Stewart TA, Leder P: Consequences of widespread deregulation of the c-Myc gene in transgenic mice: multiple neoplasms and normal development. Cell 1986, 45:485-495.

28. Liao DJ, Dickson RB: c-Myc in breast cancer. Endocr Relat Cancer 2000 7:143-164.

29. Cardiff RD, Anver MR, Gusterson BA, Hennighausen L, Jensen RA, Merino MJ Rehm S, Russo J, Tavassoli FA, Wakefield LM, Ward JM, Green JE: The mammary pathology of genetically engineered mice: the consensus report and recommendations from the Annapolis meeting. Oncogene 2000, 19:968-988.

30. Cunha GR, Wiesen JF, Werb Z, Young P, Hom YK, Cooke PS, Lubahn DB: Paracrine mechanisms of mouse mammary ductal growth. Adv Exp Med Biol 2000, 480:93-97.

\section{doi:10.1186/2047-783X-18-18}

Cite this article as: Kumtepe et al:: High serum HTATIP2/TIP30 level in serous ovarian cancer as prognostic or diagnostic marker. European Journal of Medical Research 2013 18:18.

\section{Submit your next manuscript to BioMed Central and take full advantage of:}

- Convenient online submission

- Thorough peer review

- No space constraints or color figure charges

- Immediate publication on acceptance

- Inclusion in PubMed, CAS, Scopus and Google Scholar

- Research which is freely available for redistribution 